\title{
Sustainability of the Health Management Information System in Kinondoni and Muheza districts, Tanzania
}

\author{
Mungwabi, $\mathrm{H}$. \\ University of Dar Es Salaam Library, P.O. Box 35092, Dar Es Salaam, Tanzania \\ Email:mungwabi@libis.udsm.ac.tz
}

\begin{abstract}
This study examines how Health Management Information Systems (HMIS) can be sustained in the Tanzanian context based on the experiences of Muheza and Kinondoni districts. Data for the study was collected using interviews, questionnares and document reviews. The findings show that the capability of a health facility to sustain the HMIS largely depends on ownership. Whereas respondents from government-owned facilities reported not to have enough resources to sustain the system, their counterparts in the private sector indicated that they could do so if they were asked. At the district level respondents indicated that it was a matter of incorporating all components of the system in their budgets and improving collection of internally generated revenues. The majority of respondents at both district and local levels indicated that they are committed to sustaining the system irrespective of the workload that it puts on them. Results further show that some hospital health facilities take trouble to print registers when there were shortages. At district level it was found that there were no standardized strategies to sustain HMIS. Each district made its own attempts to do so. The major constraints identified revolve around the question of funds, lack of information professionals to market the system to district administrators and limited appreciation of the HMIS as a major tool in the development of the health sector by the politicians. The paper provides recommendations on strategies to sustain the system.
\end{abstract}

\section{Introduction}

The HMIS in Tanzania was established in early 1993. The system is semi-computerized. The aim was to improve performance, the provision of health information, and the quality of data, planning and decision making in the health sector (URT, 1993). The data collected is used for planning, decision making and monitoring the performance of health services. Information collected covers the structure of health services, the diseases treated and patients' data. Studies show that the HMIS 
is constrained by many factors which include the low quality of information and lack of tools generally. This study examines a number of factors that might influence the sustainability of the system e.g the commitment of health staff, and the capacity and strategies for development and sustanance of the system based on the experiences of Kinondoni and Muheza in Dar es Salaam and Tanga region respectively.

The paper addressed the following research questions:

- Are health staff committed to sustaining the HMIS?

- Are health facilities and local governments at district level able to sustain the system?

- What strategies are in place for the sustainability of the Health Management Information Subsystems at the health facility and district levels?

- What constrains sustainability and what needs to be done for the upkeep of the system?

\section{Literature Review}

According to Katundu(1998), the concept of sustainability originated in the field of economics but it has already permeated other disciplines, including information science, where a lot of emphasis is placed among others on selection, acquisition, storage, analysis, transfer and dissemination of information. He argues that sustainability of information technology cannot be studied singly but rather together with other components which constitute the whole information system. This indicates that components of the system, such as hardware/hard copies, information/data, procedures, software and personnel, should be considered. In this study Katundu (1998) observed a number of bottlenecks, such as scarcity of resources and lack of policy. The study further recommended that libraries being information systems should facilitate information policies that accommodate effective strategic planning and IT development, assess users' IT information needs, and mobilise the support of all stakeholders and explore diversified sources of funds.

Sonoiya (2005) argues that in order to sustain health management information systems in East Africa there should be linkages with both private and public sector health institutions at various levels, issues of infrastructure should be addressed and human and institutional capacity needs to be enhanced. These remain as mere suggestions if HMIS stakeholders do nothing to sustain the system. So far there is no clue as to what is being done at various levels to sustain the system. 
Kimaro, H.C. and Nhampossa, J.L. (2004) explore the challenges involved in establishing HMIS in developing countries where most information systems projects are implemented under the auspices of donors. They observed that non-participation, incapability and demotivation of users coupled with inflexibility of the systems are the factors that make their sustainability difficult. Additionally, they observed that owing to the top-down approach in the implementation of these systems they do not reflect the actual work practice at the lower levels, which means that the commitment of workers to sustain the systems is uncertain. This study investigates further the commitment of the health staff and their capacities and attempts to maintain the HMIS in Kinondoni and Muheza districts.

\section{Research Methodology}

The study for this paper was conducted in Kinondoni and Muheza districts. Whereas the former represents an urban district the latter is a rural-based district. These districts were purposively selected because of time and financial constraints and also because they host numerous health facilities, ranging from dispensaries to hospitals owned by government and non-governmental organisations alike. Health facilities such as dispensaries and health centres were selected randomly while hospitals were selected purposively. All (72) respondents in this study were purposively selected. To improve the validity and reliability of data a combination of methods was used. Secondary data was collected through documentary review. Primary data was collected through interviews and self-administered questionnaires with both closed and open-ended questions. Data were analyzed descriptively using tabulation and cross-tabulation.

\section{Findings and Discussions}

\section{Characteristics of health facilities and staff}

The study sample included dispensaries, health centres and hospitals which were either government or privately owned.

Data in table 1 show that 13 (54.17\%) health facilities surveyed were government-owned and 11 (45.83\%) were privately-owned. These results indicate that both the government and the private sector play a key role in the provision of health services in the study districts. 
Table 1: Type of Health Facilities by Ownership

\begin{tabular}{|l|l|c|c|}
\hline District Name & $\begin{array}{l}\text { Type of Health } \\
\text { Facility }\end{array}$ & $\begin{array}{l}\text { Government and } \\
\text { Public owned }\end{array}$ & $\begin{array}{l}\text { Private and NGO } \\
\text { owned }\end{array}$ \\
\hline \multirow{3}{*}{ Muheza } & Dispensaries & 3 & 2 \\
\cline { 2 - 4 } & Health Centres & 1 & 0 \\
\cline { 2 - 4 } & Hospitals & 0 & 1 \\
\hline \multirow{3}{*}{ Kinondoni } & Dispensaries & 5 & 7 \\
\cline { 2 - 4 } & Health Centres & 3 & 0 \\
\cline { 2 - 4 } & Hospitals & 1 & 1 \\
\hline \multirow{2}{*}{ Total } & & $\mathbf{1 3}$ & $\mathbf{1 1}$ \\
\hline
\end{tabular}

Source: Field data

Educational levels and HMIS training were considered important elements for successful use of the HMIS. Forty one health workers (62.12\%) were diploma holders and 3 (4.2\%) were degree holders who can collect, analyse and interpret health data or information generated by the system. 18 (27.27\%) workers were certificates holders.

\section{Financial capacity of health facilities to sustain Manual and computer-based}

\section{Sub-systems}

An investigation into the sustainability of manual sub-systems centred around the main components that constitute the sub-system itself. These include HMIS staff, manual registers/materials and computer equipment. Other components such as data/information and procedures rely heavily on these factors which, in turn, depend on the availability of funds. Respondents in both government and privately-owned health information systems were asked to state whether they could sustain HMIS at their facilities. Findings in table 2 show that 5 (12.82) respondents at government facilities said they were able to sustain the system but the majority 31 (79.49\%) did not think so. For example, one respondent made this comment

"We cannot pay for staff training, purchase required supplies or pay the water bills let alone payr our security guards! How can we pay for HMIS?“ 
In contrast, 29 (87.89\%) respondents in privately-owned facilities observed that they could sustain HMIS compared with only 4 (12.12\%) who did not think so. Whereas government services are subsidized and underfunded the private health sector charges for the services they render, hence generating sufficient income to sustain HMIS.

\section{Table 2: Health Staff views on their ability to Sustain the HMIS}

\begin{tabular}{|c|c|c|c|}
\hline \multirow[t]{2}{*}{$\begin{array}{l}\text { Sample } \\
\text { Size }\end{array}$} & \multirow[t]{2}{*}{ Category } & \multicolumn{2}{|c|}{$\begin{array}{l}\text { Government Health } \\
\text { Facilities }\end{array}$} \\
\hline & & Frequency & Percentage \\
\hline \multirow[t]{4}{*}{$\mathrm{N}=39$} & Can Sustain & 5 & 12.82 \\
\hline & Cannot Sustain & 31 & 79.49 \\
\hline & Don’t Know & 3 & 7.69 \\
\hline & Total & 39 & 100 \\
\hline
\end{tabular}

Source: Field data

The findings indicate that government-owned health facilities cannot sustain the HMIS on their own, while privatly-owned health facilities are able and ready to pay for the registers they have been using and even for training. Muheza a designated district hospital, for instance, went ahead and printed registers instead of waiting for the government to supply them. Most staff in private facilities said that they would like government intervention in printing registers. The explanation for their varying views is simple. The government-owned facilities rely on funds given by district and municipal councils as they do not generate enough funds by themselves unlike private facilities, which generate funds and have control over that money. This shows that the cost-sharing policy, which was imposed in the past, is yet to yield significant results. The situation is aggravated by the fact that even the little that is being collected is sent to district and municipal councils as government-owned facilities have no autonomy to spend it. It is proposed that district and municipal councils should take control of HMIS. 
This study suggests there is a need to determine how much registers cost and how many of them are used in each health facility annually as as to be able to establish the amount which each health facility would be required to contribute for the upkeep of the HMIS.

"Sustainability of the HMIS in this district will be possible only if it is budgeted for like other items such as staff training and equipment and if levies are efficiently collected" These are views expressed by a respondent from one district.

This view was shared by all 6 (100\%) respondents at district level. Further investigation showed that both districts had some items relating to HMIS in their budgets though not comprehensive enough to cover all components of the system. Since districts and regions are responsible for budgeting, the more they collect the more they can allocate for the provision of health services and HMIS in particular. In 2005, for instance, Kinondoni Municipal Council collected Tshs. $3,778,820,300 /=$ from own sources against prior estimates of 5,035,092,433/= being a shortfall of 1,256,272,133/= (URT,2005:7). Futhermore, an analysis of district and regional budgets indicates that a lot of money is not spent and that very little is allocated for HMIS which was true in both the districts surveyed. For example, Muheza District Council had an income of Tshs. 6,002, 672, 676/= in 2004/2005 while expenditure was Tshs. 5,789,958,136/= leaving a balance of Tshs. $212,713,540$ that was not spent. The unspent money was sent back to the treasury, as directed by government financial regulations.

Districts and regions have two ways of financing their activities namely funds generated internally by local or municipal councils and funds from the central government. Whereas government funds are never fully spent by some of them, internally generated revenues are never collected optimally. One may therefore conclude that sustainability of the HMIS is possible provided that there is the will and commitment. Health staff have to prove that HMIS is useful and needs to be allocated adequate funds for its sustainability. This could be done through improved awareness strategies and education on the central role of HMIS in planning and decision making in the health sector. 


\section{Commitment of health staff to sustain Health Management Information System}

Health staff were asked if they were committed to sustaining the system. Previous studies have shown that health staff were overburdened by the task of collecting and processing data for the system. The findings were as follows:

Table 3: Commitment of health staff to sustaining the system

\begin{tabular}{|l|l|r|r|}
\hline \multirow{3}{*}{$\begin{array}{l}\text { Sample } \\
\text { Size }\end{array}$} & Category & \multicolumn{2}{|l|}{$\begin{array}{l}\text { Government Health } \\
\text { Facilities }\end{array}$} \\
\cline { 3 - 4 } & & Frequency & Percentage \\
\hline $\mathbf{N = 7 2}$ & $\begin{array}{l}\text { Highly } \\
\text { committed }\end{array}$ & 6 & 8.33 \\
\cline { 2 - 4 } & Committed & 41 & 56.94 \\
\cline { 2 - 4 } & $\begin{array}{l}\text { Moderately } \\
\text { committed }\end{array}$ & 5 & 6.94 \\
\cline { 2 - 4 } & Not Committed & & \\
\cline { 2 - 4 } & Total & & \\
\hline
\end{tabular}

Source: Field data

Table 3 above, shows that 50 (65.27\%) respondents are committed to sustaining the system while twenty five (34.71\%) indicated that they were not. Commitment of health staff to sustain the system is of paramount importance as they constitute the users of the system. Other people in the districts, such as administrators and politicians, who have a great say in formulating plans and budgets need to be told about the usefulnes of the HMIS by health staff. In the light of this, health staff should be motivated so that all of them are committed to sustaining the system. Mwangu (2003) argues that with the right incentives health staff will be committed to supporing the system. It is inferred, that despite its relevance, the lack of committment of a few health staff may resultt in poor quality data, which may prompt decision-makers to turn it down in terms of its support. The question is how can uncommited health staff market the system to administrators and politicians at the district level? The latter may support it only after being influenced by health staff that the system is useful, otherwise it may not be supported by decision-makers and administrators. 


\section{Strategies for the sustainability of the HMIS at health facility level}

Generally it was found that there were no standardized strategies for the upkeep of the system at health facility level. There were only ad-hoc measures that were intended to keep the system going, which include printing registers and conducting short-term training of staff.

Only 1 (4.7\%) facility prints manual registers in the event of shortage. One respondent at Muheza had this to say:

"Even now we have shortages of health registers. We plan to look for vendors who can publish these materials for us so that HMIS runs smoothly"

Other health facilities did not take the trouble to tackle this problem as they considered it to belong to the government. This feeling was shared by respondents from other districts who also suggested that printing/production of HMIS materials should be centralised at regional or district level as a strategy to overcome material delays, to speed up their distribution to health facilities, and cut down on bureaucracy. The health facilities in Kinondoni did not consider registers to be a problem because of their proximity to the headquarters. Nine facilities (37.5\%) indicated that they had tried to conduct in-house training for their staff, especially newly employed ones, to enable them to collect and process data. All 24 health facilities indicated that they met the cost of transmitting data to higher authorities themselves.

\section{Strategies for the sustainability of the HMIS at district level}

At the district level there were attempts to gain support of the administrators and politicians by incorporating HMIS-related items in the budget as well as maintenance of computer equipment.

Data revealed that both districts had begun to incorporate some items related to HMIS in their strategic plans and budget, though this was not comprehensively done. One respondent at Kinondoni district complained about the inadequacy of the HMIS budget allocation: 
“ In Kinondoni Municipality, for instance, the budget for HMIS in 2005/2006 was less than 1\% of the total district budget! How can it be sustained with this little amount, we must be serious and win the support of decision-makers".

The actual amount allocated for HMIS could not be established. Some districts and regions had already started incorporating HMIS items such as tools, equipment and stationery in district and regional strategic planning. This is because the central government was no longer supplying registers to some districts, which has led them to print their own. However, very little was being allocated for the purpose. As a result, an increase in budget allocation is suggested as nearly all districts and regions do not use up the funds that they are given by the central government for development projects. It was also found that no efforts were being made to gain support from councillors, administrators and politicians, because it is assumed that such support may not be forthcoming as this is not regarded as a core programme. This task is presently left to district medical officers. Health staff at health centres should join hands in winning the support of their councillors.

\section{HMIS Equipment and Stationery}

Some health officials interviewed in both districts reported receiving supplies from the Ministry of Health and Social Welfare and that they had started to plan for the logistics or facilities needed for the HMIS such as computers and related accessories. One member of HMIS staff at Kinondoni said:

"In this year's budget we have incorporated the purchase of two new computers, one for HMIS, and proposed Tshs. 8,000,000/= for data management“"

\section{Computer Maintenance}

Respondents from both districts reported that since its inception HMIS has experienced computer breakdowns and have had to call computer technicians to repair them. These technicians were paid by their respective local governments. However Kinondoni district has its own IT department which is responsible for maintenance and computer trouble-shooting. 


\section{Staff Training}

District medical offices surveyed had HMIS training programmes. At Kinondoni, for instance, one respondent reported that they had allocated Tshs. 4,000,000/= in their budget to train forty ( 40) health staff in 2006/2007. However, it was noted that such programmes were not conducted regularly and, as a result, a large proportion of health staff in these districts were not trained. The major constraints pointed out include lack of funds, lack of formal strategies, lack of information

professionals and health staff, poor collection of levies, lack of appreciation of the system on the part of the politicians and inflexible government financial rules and regulations.

\section{Conclusion}

Based on the research findings, government-owned health facilities are not in a position to sustain the HMIS. This is because they have no control over the funds that they have been given by the local and central governments and due to poor implementation of cost-sharing. Districts are not able to finance HMIS adequately because of inadequate planning and lack of resources, partly as a result of the poor collection of levies. Though a majority of health staff have shown committment to support HMIS they are not the ones who make decisions over its financing.

\section{Recommendations}

The study makes the following recommendations:

First, the capacity of the district management should be built by imparting skills on how to plan, budget and lobby funds for the HMIS. Second, district admininistrators and councillors should be trained on how to collect revenues efficiently to finance the HMIS. Third, through seminars and workshops district administrators and politicians should be sensitized on the importance of information to the health sector. Fourth, information professionals should be recruited at the district level to oversee the HMIS. Fifth, flexible government financial rules and regulations should be advocated to enable districts and regions to spend the allocated funds.Therefore, the government should continue supporting HMIS in government health facilities until they get control over their funds and after being able to collect substantial amounts of money from cost-sharing. Sixth, districts should enhance strategies for revenue collection and allocate a substantial amount of money to the HMIS for the printing of registers, training, maintenance and purchase of 
equipment. Finally, health staff need to have strategies in place that would win the commitment of councillors, district and regional directors and commissioners for HMIS to be adequately financed.

\section{References}

Davis,G.B. and Olson, M.H.(1984). Management Information Systems, Conceptual

Foundation, Structure and Development. McGraw-Hil. Singapore.

Koontz, H. And Weihrich, H. (1987). Management. NewYork: McGraw-Hill.

Mdoe, R. Mdoe. Health Management Information System Overview. Zonal

Workshop on Routine Data Collection System 25-27 February 2004

(unpublished report)

Ministry of Health (1999). Health Management Information System. Dar es

Salaam.: MOH, Tanzania.

Mwangu, M.A. (2003). Enhancing District Health Planning and Management in Tanzania: A Social Political Analysis of the Role of the Health Management Information System. University of Dar es Salaam. PhD Thesis (unpublished).

Sonoiya, S. East African Policy Forum on Health Management Information System: Forum Report. 23-24, May 2005.

The United Republic of Tanzania (2002). Health Statistics Abstracts. Dar es Salaam: Health Information and Research Section, Tanzania.

Kimaro, H.C. and Nhampossa, J.L. (2003). Analyzing the problem of Unsustainable Health Information Systems in Less-developed Economies: Case Study from Tanzania and Mozambique.

Sclafani, J.A.Sustainability: A Client-Driven Model.

Initiatives/JSI Research \& Training Institute http://www.jsi.com/intl/init/client.htm

The United Republic of Tanzania (2005). Report of the Controller and Auditor General on the Financial Statements of Kinondoni Municipal Council for the Financial year that ended 30th June 2005. Dar es Salaam:The Controller and National Audit Office. 